\title{
Supporting Mental Health and Psychosocial Wellbeing Through Social and Emotional Learning: A Participatory Study of Conflict-Affected Youth Resettled to the U.S.
}

\author{
Lindsay Stark ( $\sim$ lindsaystark@wustl.edu ) \\ Washington University in St. Louis \\ Mackenzie Robinson \\ Washington University in St. Louis \\ Alli Gillespie \\ Washington University in St. Louis \\ Jeremy Aldrich \\ Harrisonburg City Public Schools \\ Wafa Hassan \\ Global Educational Excellence \\ Michael Wessells \\ Columbia University \\ Carine Allaf \\ Qatar Foundation International \\ Cyril Bennouna \\ Brown University
}

\section{Research Article}

Keywords: Adolescents, social emotional learning, mental health, psychosocial wellbeing, refugees, participatory ranking methodology

Posted Date: January 13th, 2021

DOI: https://doi.org/10.21203/rs.3.rs-137369/v1

License: (c) (i) This work is licensed under a Creative Commons Attribution 4.0 International License. Read Full License 


\section{Abstract}

Background A growing literature has drawn attention to the central role that schools play in supporting the adjustment of resettled refugee youth and promoting their mental health and psychosocial wellbeing. In particular, the recent proliferation of school-based social and emotional learning (SEL) initiatives presents an opportunity to strengthen supports for resettled adolescents. This participatory research study aims to understand how high school students resettled from countries in the Middle East and North Africa region are experiencing the challenges and opportunities of acculturation and the ways in which they believe schools can better support them in this process.

Methods We analyzed primary data collected during focus group discussions as part of the SALaMA study. During these discussions, we used participatory ranking methodology to elicit adolescents' suggestions on how high schools can better support students both academically and psychosocially after resettlement. Fourteen focus group discussions were held with male and female adolescents (14-20 years), selected purposively across six public high schools in Harrisonburg, Virginia, Austin, Texas, and Detroit, Michigan. Participants offered suggestions and then ranked them in order of importance using consensus ranking.

Results Thematic analysis of the PRM results across sites produced a wealth of suggestions centered around three broad themes, namely: skills related to navigating social and academic challenges, culturally responsive teaching, and socially and culturally equitable learning environments.

Conclusions Findings reported illustrate limitations of the conventional, universal SEL model and shed light on how schools can adapt transformative SEL strategies to serve their students better, especially newcomers from conflict-affected countries.

\section{Background}

The number of forcibly displaced persons worldwide was estimated to have reached nearly 80 million as of 2019 , with $40 \%$ of these persons under the age of 18 (1). The same year, over a quarter of the 24,800 refugees resettled in the U.S. had originally fled countries such as Iraq and Syria (2) in the Middle East and North Africa (MENA) region. Various studies have documented the heightened mental health and psychosocial wellbeing risks among forcibly displaced children and adolescents (3-5). If left unattended, these risks may impact adolescents' life course by compromising the development of problem-solving, coping, and relationship-building skills and disrupting identity formation ( 3 , $4,6-8)$. Daily stressors and supports in the receiving country may further affect the mental health of adolescents after resettlement.

A growing literature has documented the central role that schools play in supporting the adjustment of resettled newcomers (9). Schools can be an opportune setting for interventions that foster positive coping mechanisms, facilitate increased access to social support, and promote acculturation as a bidirectional process requiring adjustments from newcomers and the receiving community (10), all of which have been shown to improve adolescent wellbeing (11). In particular, schools can serve as critical points of care and referral for specialized mental health and psychosocial supports (MHPSS), helping to overcome numerous barriers to services, including stigmatized attitudes towards mental health, inadequate resources, and limited access to providers among resettled families (12-16).

The proliferation of school-based social and emotional learning (SEL) programs and policies in recent years presents an opportunity to strengthen supports for resettled newcomers. SEL may refer to any number of frameworks and interventions that utilize approaches within the non-cognitive domain, or skills outside the academic realm (17). One of the most commonly used SEL frameworks in the U.S., the Collaborative for Academic, Social, and Emotional Learning's (CASEL) "universal SEL" model, aims to enhance students' core competencies in five areas: self-awareness, self-management, social awareness, relationship skills, and responsible decision-making $(18,19)$. The specialized curriculum is designed to foster development in multiple domains of resilience, interpersonal conflict and anger management, relationshipbuilding, and problem-solving. In addition to classroom components, the universal SEL model includes interventions focused on adult SEL, school climate, and partnerships with families and communities (20).

The evidence suggests that universal SEL promotes sustained positive mental health and psychosocial wellbeing among adolescents, including increased prosocial behaviors, reduced emotional distress, and improved academic performance (21-24). SEL programming may provide a unique opportunity to create a more supportive environment for newcomers, and especially those arriving from conflict-affected contexts, who may benefit from their school's attention to values such as building social awareness and developing positive, caring relationships among students and school staff $(25,26)$.

Despite its potential for supporting acculturation, the conventional SEL model has been criticized for its limited attention to the experiences, needs, and capacities of historically marginalized and racialized groups, including immigrants $(27,28)$. Specifically, critics have argued that the SEL core competencies and curriculum are largely grounded in white, middle-class American ideals that risk perpetuating ethnic-racial alienation and discrimination (29-32). Efforts to improve school climate have been seen as not doing enough to emphasize sociocultural equity and inclusion $(33,34)$. 
In recent years, several efforts aimed at addressing the limitations of the conventional model have included a "transformative SEL" approach, which incorporates the development of positive ethnic-racial identity and conducts critical analyses of privilege and power within the five SEL competencies $(29,35-38)$. Transformative SEL also tends to be more aligned with MHPSS frameworks developed for use with conflictaffected populations $(39,40)$. These frameworks place importance on building young people's sense of identity to enhance self-efficacy and belonging. They also recognize youth voice and participation and the value of cultural resources in fostering wellbeing holistically (40).

The inclusion of these principles substantially improves on the conventional SEL model, increasing its potential relevance to the experiences of student newcomers, like the ones in this study, from conflict-affected countries such as Iraq, Syria, and Yemen. Greater attention to the lived experiences, perspectives, and ideas of these young people may provide critical insight for making school-based supports more inclusive of refugee adolescents. We used participatory research methodologies in this study to understand how newcomer students from conflictaffected countries in the MENA region experience the challenges and opportunities of acculturation. Guided by the emerging transformative SEL framework, we also elicited students' interpretations, ideas, and priorities regarding how their schools can better support them in this adjustment process. This paper adds to the current literature by centering student perspectives on how schools can more effectively serve the social, emotional, and academic needs of newcomer adolescents from the MENA region.

\section{Methods Setting}

Data were collected as part of the Study of Adolescent Lives after Migration to America (SALaMA) to assess the mental health and psychosocial wellbeing of adolescents from the MENA region resettled in the U.S. (41-43). The study was conducted in six public high schools across three sites: Harrisonburg, Virginia; Austin, Texas; and the Detroit Metropolitan Area (DMA), Michigan. These sites were selected purposively based on pre-existing collaborations, a history of resettling refugees from the MENA region, and interest from local school systems $(41,42)$.

Collectively, Virginia, Texas, and Michigan resettled 123,288 refugees in the U.S. between 2008 and mid-year 2020 (44). In 2015, 57.8\% of refugees and special immigrant visa (SIV) holders in Michigan were from the MENA region, compared to $29.5 \%$ in Virginia, 20.2\% in Texas, and $15.6 \%$ nationally (45). Today, Harrisonburg City Public Schools (HCPS) serves around 6,400 students, $46 \%$ of whom were born outside the U.S. Around $9 \%$ of HCPS's student population speaks Arabic and 6\% speak Kurdish (46). Austin Independent School District (AISD) serves around 80,000 students, $27 \%$ of whom are English language learners (ELLs) with Arabic being the most common language after Spanish (47).

While Harrisonburg and Austin are leaders in their states for refugee resettlement, the DMA was selected as a key site because it is well-known as having among the largest Arab ethnic enclaves in the U.S. (48). These participants attended one of three Global Educational Excellence charter high schools in the DMA, wherein about $53 \%$ of students are English Language Learners, with a significant percentage of students being resettled refugees or asylum-seekers from conflict-affected countries in the MENA region (49)(50).

\section{Participants}

Adolescent students (aged 14 to 20 years) were selected purposively at each school to participate in gender-stratified focus group discussions (FGDs) (Table 1). School-based staff assisted the research team in identifying and recruiting students who had arrived from conflictedaffected MENA countries in the past five years. Due to the unique demographics of the population in Michigan, we included some adolescent participants who were born in the U.S. or who had been in the U.S. for longer than five years, but whose families had emigrated from the MENA region; further information on participant selection and recruitment is available elsewhere (41). All FGDs in Austin and Harrisonburg were held exclusively with students born outside of the U.S. Across sites, the number of participants in each session ranged from three to eight. 


\section{Data Collection}

\begin{tabular}{|c|c|c|c|c|}
\hline \multirow[t]{2}{*}{ Location } & Austin & Harrisonburg & Michigan & All Sites \\
\hline & $\mathrm{n}$ & $\mathrm{n}$ & $\mathrm{n}$ & $\mathrm{n}(\%)$ \\
\hline \# FGDs & 3 & 3 & 8 & $14(100)$ \\
\hline \multicolumn{5}{|l|}{ Sex (Age) } \\
\hline Female $(14-20)$ & 3 & 9 & 19 & $31(44.9)$ \\
\hline Male (14-19) & 10 & 8 & 20 & $38(55.1)$ \\
\hline \multicolumn{5}{|l|}{ Country of Origin } \\
\hline Iraq & 9 & 12 & 3 & $24(34.8)$ \\
\hline Syria & 3 & 3 & 9 & $15(21.7)$ \\
\hline Yemen & 0 & 0 & 12 & $12(17.4)$ \\
\hline United States & 0 & 0 & 10 & $10(14.5)$ \\
\hline Jordan & 0 & 0 & 3 & $3(4.3)$ \\
\hline Sudan & 1 & 2 & 0 & $3(4.3)$ \\
\hline Palestine & 0 & 0 & 2 & $2(2.9)$ \\
\hline Total Participants & 13 & 17 & 39 & $69(100)$ \\
\hline
\end{tabular}

Informed consent was obtained from all participants. For participants under the age of 18, written parental informed consent was obtained prior to approaching students for written informed assent. Students 18 years or older consented directly. Two trained facilitators led each focus group discussion. Participants were informed that the activity would take approximately 1.5 hours and that all identifying information would be omitted during transcription. All group discussions were audio-recorded and took place at the schools in private rooms made available by school staff. While most students participated in English, an Arabic interpreter was present as needed.

Fourteen group discussions were held with a total of 69 adolescent participants representing nine countries in the MENA region. Exercises commenced with a discussion of students' experiences at school and home using a semi-structured discussion guide, including broad framing questions such as, "How does a new student at this school make friends?" and "How would you describe your relationships with teachers and other school staff?"

Following this discussion, facilitators initiated a participatory ranking method (PRM) exercise (51). Evidence highlights PRM as an effective consensus methodology with children and adolescents; the approach elicits opinions and ideas to ensure that intended outcomes are in line with participant priorities (52-54). Participants were invited to answer the question "How can high schools better support students who have been resettled from conflict-affected, Arab-majority countries?" by free-listing suggestions for improved academic and psychosocial supports. The facilitators encouraged open discussion and confirmed there was sufficient agreement among group members. Once confirmed, a participant volunteer wrote a short, representative phrase agreed upon by the group for each suggestion. Facilitators validated participants' interpretation of each concept before proceeding to the subsequent suggestion. Once the group had decided on a maximum of seven suggestions, they were asked to rank them collectively from 'very important' to 'least important.' Participants were asked to explain the decisions behind their comparative rankings and adjust until consensus was reached. The note-taker recorded participant dialogue throughout the processes of free-listing and ranking.

\section{Analysis}

All PRM suggestions provided by participants and their corresponding rankings were transcribed into a spreadsheet. Two coders reviewed results and conducted thematic content analysis to explore these areas of student-identified supports in greater depth (55, 56). Once the common themes were established, coders categorized results according to these themes, with frequency, median, and mean rankings calculated, with "one" indicating the highest priority. The researchers also drew on transcripts from the FGDs to inform the thematic content analysis, elucidate meaning, and compare prioritized supports across study sites.

\section{Ethics}


Multiple measures were taken to ensure that the research was conducted in an ethical manner, with particular attention to securing voluntary, safe, and meaningful participation $(42,57)$. Participants were offered a small gift card for their time and input upon completion of the FGD.

The study was reviewed and approved through the Columbia University Medical Center IRB (IRB-AAAR7830), the Washington University in St. Louis IRB (IRB-201905151), AISD's Department of Research and Evaluation (R18.62), the Superintendent of Schools at HCPS, and the Director of GEE Schools. All methods were carried out in accordance with relevant guidelines and regulations.

\section{Results}

Analysis of the PRM results across sites produced a wealth of suggestions pertaining to seven main themes of supports, which correspond closely to the CASEL model and underscore the relevance of several elements of transformative SEL to the lives of newcomer students (see Table 2). These themes tended to cluster within three core elements of the SEL framework, namely: 1) Student SEL Competencies, 2) Adult SEL, and 3) School Climate.

Table 2

School support themes elicited during PRM exercises

Theme
1. English Language Support
Ways to enhance English comprehension and communication skills as a pathway to integration and
advancement.

advancement.

\section{Orientation to Rules and Norms}

Communicating vital information, including information on social norms, school rules, systems and operations, and available resources.

\section{Peer Support}

Newcomer students desire to develop positive relationships with peers (both other newcomer and U.S.born students).

\section{Psychosocial Wellbeing}

Ways in which schools as a whole promote resiliency among newcomer students.

\section{Teacher Support}

Key attributes of teachers and staff to instill confidence, trust, and foster success among newcomer students.

\section{Sense of School Belonging}

Ways for schools to enhance newcomers' sense of belonging

\section{Cultural Responsiveness}

The quality of school support related to social identity, language, customs, beliefs, and values identified by newcomer students as helping them to feel welcome, to acclimate, and to succeed.

\section{Student SEL Competencies}

Participants identified two primary pathways through which schools supported young peoples' identity formation, self-efficacy, and sense of belonging-central principles of transformative SEL. First, students emphasized the process of developing a positive self-image through language acquisition. Second, students felt a sense of belonging that resulted from strengthened peer support networks.

\section{Confidence and positive self-image through English language acquisition.}

Newcomer participants described how enhancing their ability to identify their strengths and develop social confidence and self-esteem allowed them to progress both academically and socially. This strengthened view of self was often tied to the success of English language acquisition. One student explained that building the "confidence to learn English" allowed him and his peers to "introduce themselves" and "do activities where they could interact with other people" (Michigan, Boy). Another student articulated that switching from primarily English as a Second Language (ESL) classes into regular classes encouraged him to "speak out now" instead of "just [hiding] in your shadows" (Harrisonburg, Boy). At the same time, a negative self-conception was sometimes tied to the ongoing challenges of language acquisition. One student explained this association: 
So, let's say that the teacher picks on the person that doesn't really know how to speak English and he pronounces the word wrong, they'll just start laughing. Yeah, it's just sticky. And the dude doesn't raise his hand up for the rest of the hour. Kinda ruins their self-esteem. (Michigan, Boy)

Students emphasized how language acquisition promoted an ability to regulate self-defeating emotions and manage stress associated with acculturation, helping them to develop and achieve goals. One student described how she pushed herself to accelerate English language learning as her teacher taught her more vocabulary. While at first "people [were] rude to me since I was the only Arabic girl," she said, language acquisition empowered her to "speak up against them," making her feel "a lot better now" (Austin, Girl). Another student mentioned that he and other students "learn English through robotics," which "gave us something very big to dream, bigger than we can" (Michigan, Boy). English language support resonated strongly with students as a key skill to build confidence and to promote growth and was notably the only theme identified and discussed in every focus group conducted.

\section{Supportive peer relationships.}

The desire to develop positive relationships with peers was the third-most frequent theme arising from the participatory ranking activity. Newcomer students described feeling supported when schools fostered relationships with other newcomers from the MENA region. For example, a student who had been in the U.S. for several years described being asked by a counselor to speak with a recently arrived middle schooler who "was lost" and "needed someone to explain everything." A week after the older student reassured the newcomer that "it's gonna be fine, I was like you," the counselor called to let her know that the newcomer was "better... and talking to people more" (Austin, Girl). Foreignborn students who had been in the U.S. longer often took it upon themselves to help more recent arrivals feel welcome, make new friends, and identify academic and non-academic supports. One student, for instance, described how he served as a bridge for recently arrived newcomer students:

Even for the kids that, uh, came from overseas after us, and they don't know how to speak English, we used to take them with us and chill with them and introduce them to other kids who don't even speak English so they would feel comfortable. First day, second day, third day of school... they would be like friends with like, half of the school. (Michigan, Boy)

Students attested to the importance of being able to communicate effectively and meaningfully with peers, either in their native tongue or in English. As one newcomer student from Yemen attested, "I imagine when I have language, I go right to [other students] and talk to them if I want anything, but I'm shy a little bit because I don't have the language (Michigan, Girl). Many newcomer students appreciated when U.S.-born students were curious about their culture in a way that was friendly and respectful. For example, one participant mentioned "a lot of people telling me 'I like your hijab, like the way you wear it,"' with some asking "how did you come to here and where are you from... [to] start a conversation with me" (Harrisonburg, Girl).

\section{Adult SEL and Cultural Responsiveness}

Students emphasized the importance of the social and emotional competence of their adult educators, and specifically their ability to recognize and be compassionate towards the particular challenges of acculturation. Not only did students identify the need for educators capable of delivering culturally responsive lessons and promoting inclusive learning environments, but they also highlighted educators as general psychosocial support resources for students. The two sub-sections below explore these themes further.

\section{Supporting student mental health and psychosocial wellbeing.}

Students viewed educators as being influential in promoting students' sense of psychosocial wellbeing. Indeed, psychosocial wellbeing was the highest ranked theme among the PRM results. Newcomers considered educators to be frontline psychosocial supports that could provide advice and guidance on how to cope with school stressors and challenges. One student described how providing U.S.-born students with "cultural information" about newcomers' home countries, beyond just teaching about their histories of political conflict with the U.S., might increase knowledge and perceptions that other students "care about you," but emphasized that "it's not gonna help you as much as the teacher's support" (Austin, Boy).

Self-awareness and empathy among educators played a central role in many students' decisions to seek support. In focus groups, students often mentioned specific teachers whom they collectively agreed were dependable. In one such group, for example, a student explained how "when you have a problem and you go to Miss _, she's really into it and she's trying to help us with it," elaborating that "when you see that you can trust her, she could really help you" (Harrisonburg, Girl).

In addition to identifying specific school personnel as sources of support, students also discussed the importance of particular faculty and staff positions. For example, students recognized the vital role of school counselors in developing positive coping mechanisms for the challenges they faced. Voicing a common sentiment, one student reported she would "go to [the counselor] sometimes... when I have 
problems" (Michigan, Girl). Another participant described counselors as "the best thing ever" and mentioned that her counselor would "keep everything you say to herself, help you out, and make you feel better" when she sought assistance with school and housing-related issues (Harrisonburg, Girl).

Even though many students saw the potential for multidimensional support from academic counselors, a number of students felt underserved by the few counselors accessible within their schools. One student in Harrisonburg felt that her "counselor is never there" and was "always busy," despite the student "[working] so hard to find her" (Harrisonburg, Girl). Students in Austin shared this sentiment, explaining that "counselors [are] so busy always," often directing students to "go look at [resources] online" because they "don't have time" (Austin, Girl). Multiple participants mentioned a lack of counselors utilizing language interpretation services during their meetings, while one student found his counselor to be discouraging when he wanted to take an honors class, asking "Are you sure you're ready? You might fail the class." The student felt that his teacher had expected less of him, "just because I didn't speak English" (Harrisonburg, Boy).

Participants voiced a desire for more proactive efforts from school staff to prevent bullying, which they considered to be one of the core threats to their wellbeing. One student suggested that teachers form "some kind of protection group... that will talk to the person that you're getting picked on by" and "show them what's actually going on in that person's life and how it's affecting people, like how he's acting before and how he's acting now since he's getting picked on" (Austin, Girl). The student also emphasized the importance of promoting empathy, proposing that teachers ask perpetrators of bullying to consider, "if they went to a foreign country and they had to go through that, [would] you want [bullying] to happen to them?"

\section{Culturally responsive learning environments.}

Students expressed a desire for teachers and school staff to maintain a responsive and respectful environment where they demonstrate their equity literacy, especially related to the acculturative challenges affecting MENA students. A student in Michigan - who had educators both with and without his same cultural heritage - appreciated when "teachers get to know each other, sit down, talk to each other... they all merge into one relationship and that makes them all treat students the same way, in a respectful way" (Michigan, Boy).

One student described a tense situation in one of her classes where the teacher attempted to quell an argument between her Iraqi and Kurdish classmates over the autonomous Kurdistan region in Iraq, a highly disputed territory that has been the subject of an independence struggle among Kurds:

I've seen a fight about culture. Between an Iraqi girl and a Kurdish girl in my class. When my teacher was talking about it, it led to a fight... They were saying, 'Oh, I have [a] country and it's like, it's not [just] a name, but it's there.' So, they fought over that... The teacher, he was trying to explain to them first, that it's true that there's no country, but there's still Kurdish people that exist that have language. It's just that they don't have a territory. And he told [them], 'There's no reason why you guys should fight'...he talked to them after [class]. (Harrisonburg, Girl)

In this situation, the teacher attempted to intervene and to ensure both students felt heard and respected. Students expressed feeling discouraged and alienated when teachers employed culturally insensitive or assimilationist methods, such as enforcing an English-only classroom, shaming students for their English language level or accent, or drawing unwanted attention to a student's perceived social identity. One student described how some teachers made it difficult for her and other newcomer students to participate in class by continually telling them “'Speak English! Speak English!' but nobody can, so it's really hard” (Michigan, Girl). Another student mentioned how educators sometimes spoke condescendingly to newcomers, expressing that "just because [students] don't speak English, they feel like they have to act with them like kids" rather than "talking to us like an adult" (Harrisonburg, Boy).

Some students appreciated tailored supports, including when teachers and staff offered accommodations for religious practices, such as "[cutting] back on the homework" and "[giving] us easy assignments" during the month of "Ramadan, where Muslims fast for around 17 hours a day" (Michigan, Boy). However, a few students reported feeling singled out as needing special protection by teachers and staff, who may have been trying to provide well-intentioned supports. For instance, students recalled how a classmate with a disability and a refugee background was treated at their school. One student said that "the principal and the teachers would point him out, they would try to be nice, but they would give him special treatment that you could tell he didn't want" (Michigan, Girl), with another student responding that "they know they're special, but don't make them feel [ashamed or embarrassed] in front of everybody" (Michigan, Girl). These responses describe a fine line between accommodating newcomers in a welcoming manner, in which educators recognize and respond to newcomers' preferences, and stigmatizing newcomers through what participants called "special treatment," where educators impose their own understanding of what newcomers need.

\section{School climate and promoting school belonging}

Students appreciated warm and welcoming environments in their new schools and emphasized structural factors that promoted such a climate. These factors aligned with two subthemes: positive reception from faculty and students and schoolwide programming measures. 
The following two subsections explore how students' sense of school belonging varied based on these factors.

\section{Welcoming school climate.}

Students valued when their schools cultivated a welcoming context of reception for newcomers and supported their adjustment to their new environment. Compared with students in Austin or Harrisonburg, students at schools in Michigan seemed to encounter a relatively more welcoming environment upon arrival to the U.S., likely due, at least in part, to the composition of the student body and the large number of Arabic-speaking teachers and staff. For example, a participant in Michigan described feeling connected with other students who "know the feeling and will try to help you, they will try to pick you up," as well as staff who "help us a lot" and "know how to speak Arabic." Such a welcoming climate made the school "a great place to start, and I'm glad I started [here]" (Michigan, Boy).

When asked how newcomer students made friends at their new school, many students across study sites described strong initial connections with other newcomers. One student stated that it was easier to make friends with other students "from your same ethnicity", because "you have many things in common, you feel more comfortable" (Harrisonburg, Girl). That being said, students believed school environments that fostered friendships across the student body, and not just with students of similar backgrounds, to be an important determinant of the ease and rate of their acculturation.

When students felt there was clear division of friend groups based on background, they also revealed a diminished sense of belonging. One student expressed:

I'm saying after you learn English even, you're gonna get bullied when you have that accent. You have that not a Black-looking person and not a white. You have that Asian look or Middle Eastern, especially Yemeni look. And it's hard because you're not accepted by the white people or the Black people. You're not accepted by the Americans, because you don't speak the language. You don't get accepted by the Yemenis because you start changing now. You're not a Yemeni anymore. (Michigan, Boy)

As expressed above, students did not always feel welcomed in their new schools. One participant described his own negative experience with his initial school environment, noting that "nobody will actually stop me to meet" and that "everybody is staring at me, like oh my gosh" (Austin, Boy). Another student noted that as a newcomer, "you feel like you're not human." He went on to explain that "if you are not feeling welcome, then sometimes you'll feel like it just hurt me this time, I wanna suicide" (Austin, Boy), demonstrating the sometimes severe impact of school climate on individuals' mental health.

\section{Schoolwide measures.}

Formal initiatives also supported students' sense of belonging within schools. For starters, providing critical information to newcomer students on social norms, school rules, operations, and available resources upon arrival was deemed vital for adjustment and for expanding academic and social opportunities. In fact, orientation to rules and norms was the second most frequent suggestion that students produced in participatory ranking activities. When communication of rules and norms was insufficient, a series of negative consequences followed: Students who had been placed in a lower grade during their initial enrollment after resettlement thought that their level of education was underappreciated; students were disciplined for behaviors they did not understand had violated the rules, such as speaking their primary language; and they missed opportunities to enroll in classes or extracurriculars that interested them and that could advance their educational and eventual career success. One student raised a series of questions that she felt she had to figure out on her own:

Why are we going to classes instead of teachers coming to us? Why do we have homeroom? How do we get most of the credits without having to go through three or four years of high school? How can we make those credits cut shorter so we can graduate earlier? Those questions, you kind of figure them out as you get older. Time fixes things. (Austin, Girl)

Another student mentioned being "in a lot of trouble 'cause I didn't know [all the new rules]," emphasizing that teaching newcomers these norms should be "the first thing" schools do (Michigan, Boy). Students appreciated initiatives such as Harrisonburg's Peer Leader Program, in which students "learn about each other and [from] where they came," (Harrisonburg, Boy), as these programs were thought to create a welcoming space for students to share experiences and information, exchange advice, and form relationships within the broader community.

Newcomer students also valued formal opportunities to access and share information about their countries of birth and cultural heritage in a manner that did not ostracize them, but rather recognized their dignity. These participants wanted schools and teachers to educate their classmates about the rich national histories of their countries of origin. One student expressed that learning "about my country, about my culture" made him feel like "oh, they acknowledge me... they want to learn more about it so they can learn more about me." When teachers and peers made the effort to talk about his country out of "all the countries in the world," it made him "feel kinda special" (Austin, Boy). A student in Michigan recalled a particular initiative his school took to promote cultural inclusion and appreciation, called "Multicultural Day:" 
Each student picks a country... and you basically have to research the history, put it all on a poster and build something... I did Jordan. I built a soccer field, 'cause their culture is soccer. Each year, you choose a different country and the day that we have to present, the whole school's different. It's filled with different cultures and each person that comes to your station, you present to them everything you learned and you show them the activity. (Michigan, Boy)

Rather than discussing the wars taking place in their home countries, students wanted more positive representation of their homelands reflected in curricula. When asked what such representation could look like, one student responded: "I kind of don't like the word 'history,' 'cause it involves a lot of stuff, including [a lot of] wars. It's not that fun. But giving [other] information can be interesting cause you're talking about different cultures, not giving [just] history' (Austin, Boy).

In addition to positive representation in curricula, students appreciated inclusion in classes and extracurricular activities. Although classroom programming for newcomers varied across study sites, a common practice involved placing recently arrived students in sheltered instruction for a given period to scaffold their language skills and content-area knowledge before integrating them into the general student body. In one PRM focus group activity, however, a student suggested that newcomers join the wider student body in regular, English-based classes instead of being "separated" from U.S.-born students throughout the day. The student explained that "if you only put [newcomer students] all in one class, they won't be able to [experience] their new life." She elaborated that full integration would "help them gain confidence into opening up and into the new world" (Michigan, Girl).

Further, newcomer students described feeling confident and accepted when they participated in student groups, teams, and clubs. As one student shared, "everyone start[ed] picking me as their friend" after his soccer coach selected him to play in a game (Austin, Boy). Another student highlighted how participation on the robotics team allowed him to achieve goals: "we make a team together, we work together, and we have a reward last year for the [fastest] improving team in the last two years. We go from last to top 10" (Michigan, Boy). Students were also members of cultural heritage groups. One student described joining his school's "Arab Student Association, so you can do sports in it and they can help you with student mentors" (Michigan, Boy).

\section{Discussion}

Over the course of their displacement and resettlement, conflict-affected adolescents may face countless stressful life events and acculturative stressors that heighten their risk of adverse mental health and psychosocial wellbeing outcomes. As the central institutional support in adolescent lives, schools play a crucial role in welcoming young newcomers and promoting their adjustment $(3,9)$. Participants in this study felt that schools supported newcomers' mental health and psychosocial wellbeing in numerous ways. They highlighted how schools fostered a positive self-image and promoted healthy peer relationships, how educators served as frontline psychosocial supports, and how administrations took a range of schoolwide measures to improve climate and students' sense of belonging. Notwithstanding these considerable efforts, the participatory ranking approach empowered participants to share experiences and ideas that could extend and complement current supports. Enhanced English language support, orientation to rules and norms, peer and teacher support, and cultural responsiveness were all considered necessary for improving sense of school belonging and psychosocial wellbeing. While there was not a wide range in mean or median rankings, mental health and psychosocial supports emerged as the highest ranked theme and English support was the only theme mentioned across all groups.

The findings demonstrate the value of a transformative approach to SEL-with its emphasis on inclusion, equity, and positive ethnic-racial identity-formation-in enhancing newcomer wellbeing. At the same time, the various perspectives of MENA youth also have the potential to help fill current gaps in the model in terms of its applicability to newcomer students. Beyond the competencies addressed in existing SEL models, students spoke to the crosscutting, deleterious effects of the challenges they encountered as newcomers that undermined their sense of self-efficacy and ability to manage acculturative stressors, including microaggressions and discrimination. They emphasized the impact of culturally responsive teachers on their psychosocial wellbeing and appreciated when teachers connected them with other students and listened to their problems. Students also pointed to how teachers might modify their behavior to ensure positive student-educator relationships and inclusive learning environments. For example, assimilationist educational approaches that discouraged and even punished native language usage frequently made students in this study feel intimidated and demoralized. Evidence shows that educators who exhibit an 'assimilationist' stance in regard to newcomer students' acculturation process, with the belief that they should strictly abide by the norms of their new school and the dominant culture of their new country, can have negative effects on sense of belonging and academic success $(26,58)$. Thus, our findings illuminate the need to expand the transformative SEL framework to pay more attention to questions of acculturation and cultural responsiveness (see Fig. 1).

On a broader scale, participants lauded schoolwide efforts to create and maintain systemic supports for newcomers and considered these measures a way to promote a greater sense of school belonging. Recognition of students' cultural identities, without reducing them to their newcomer/refugee status, was deemed vital in mitigating feelings of 'otherness' within schools and fostering peer inclusion. Students

Page 9/15 
responded positively when representations of their heritage cultures were presented as assets, rather than as flattened caricatures. Experts argue that inattention to matters of identity, belonging, and inequality in conventional schooling and in universal SEL has a variety of negative consequences, including increased acculturative stress and a compromised development of a positive ethnic-racial identity (29, 59). Research suggests that a positive sense of ethnic-racial identity can help students to develop and employ "cultural repertoires" that allow them to build and sustain self-esteem and belonging, ultimately leading to resilience against marginalization (60). Children and adolescents are at a greater advantage when developing these repertoires, as their position allows them to mold the social environment for future generations (59).

A comparison of findings across study sites particularly highlights the impact of positive ethnic-racial identity on wellbeing for newcomer adolescents resettled in Michigan's ethnic enclave, where Arab cultural practices are embraced by schools and educators. Garner et al.'s reconfiguration of the SEL model emphasizes the role of a school's sociocultural context, and placement within the community it serves, in promoting students' SEL competencies (61). Schools' geographic location and racial and ethnic composition are considered "direct influencers" of student wellbeing, according to this model (61). Whereas participants in Austin expressed difficulties when facing bullying from students from other racial/ethnic groups, analysis of peer support in Michigan reported elsewhere was found to include two-way benefits of friendships between U.S.-born and foreign-born adolescents with shared cultural heritage (43). Findings also suggest that schools' ability to provide safe environments, including bullying prevention, may be an important factor in creating a welcoming environment for newcomer students. Such factors and their influence on psychosocial wellbeing speak to the urgency of efforts to improve on the conventional universal SEL model and the importance of listening to the experiences and ideas of students from a wide range of backgrounds (31).

We recognize the limitation in analyzing student perspectives alone, especially as social desirability may bias what adolescents choose to share in peer focus groups, though we are encouraged by how forthcoming students were about both negative and positive experiences in these schools. It is also valuable to consider the perspectives of educators, parents, and district officials to understand the full picture of current and future schoolwide measures aimed at supporting students' mental health and psychosocial wellbeing (26). Overall, student ideas and feedback reaffirm the critical importance of efforts to improve SEL's attention to sociocultural equity, inclusion, and participation, principles that may be present to varying degrees across the wide range of SEL models and programs being used around the U.S. (17). Students' knowledge and feedback give insight as to how SEL improvements might help to ease processes of resettlement and acculturation. Further, the wide range of suggestions emerging from our participatory approach illuminates the value of expanding the evidence base on the direct preferences of adolescent refugee youth. These findings are by no means representative of the full range of perspectives and experiences among conflict-affected youth from the MENA region resettled in the U.S. Future research should prioritize culturally responsive quantitative methods to assess the experiences of this under-studied population and to evaluate the continuous impact of SEL interventions on their identity formation, agency, belonging, and, ultimately, their mental health and psychosocial wellbeing $(62,63)$.

\section{Conclusion}

While ample evidence supports the important role that schools play in promoting forcibly displaced adolescents' mental health and psychosocial wellbeing, minimal literature to date has documented newcomer students' perspectives and recommendations on how schools can serve them more effectively. The findings from this study emphasize the importance of including student voices in identifying ways to improve school supports for their ultimate benefit, especially for students from historically marginalized backgrounds. School initiatives based on the SEL models, and especially transformative SEL, show great promise in addressing gaps, though students illuminate the need for stronger inclusion of MHPSS, English language supports, and sociocultural equity with educators and peers. These findings may not only advance the refinement of the transformative SEL model, but also inform efforts to improve school-based psychosocial interventions for newcomer adolescents and ultimately students' mental health and wellbeing.

\section{List Of Abbreviations}

AISD: Austin Independent School District

CASEL: Collaborative for Academic, Social, and Emotional Learning

DMA: Detroit Metropolitan Area

FGD: focus group discussion

GEE: Global Educational Excellence

HCPS: Harrisonburg City Public Schools

MENA: Middle East and North Africa

Page 10/15 
MHPSS: mental health and psychosocial supports

PRM: participatory ranking methodology

SALaMA: Study of Adolescent Lives after Migration to America

SEL: social and emotional learning

SIV: Special Immigrant Visa

U.S.: United States

\section{Declarations}

\section{Ethics approval and consent to participate}

The study was reviewed and approved through the Columbia University Medical Center IRB (IRB-AAAR7830), the Washington University in St. Louis IRB (IRB-201905151), AISD's Department of Research and Evaluation (R18.62), the Superintendent of Schools at HCPS, and the Director of GEE Schools. Informed consent was obtained from all participants. For participants under the age of 18, written parental informed consent was obtained prior to approaching students for written informed assent. Students 18 years or older consented directly. The published study protocol (41) contains further information on informed consent and assent processes.

\section{Consent for publication}

Not applicable.

\section{Availability of data and materials}

The datasets generated and/or analyzed during the current study are not publicly available due to IRB restrictions but are available from the corresponding author on reasonable request.

\section{Competing interests}

The authors declare that they have no competing interests.

\section{Funding}

This work was supported by Qatar Foundation International (QFI). The funders contributed to study design, but did not contribute to data collection, analysis, publication decision, or manuscript preparation.

\section{Authors' contributions}

Study Design: LS, CA, CB. Data Collection: MVR and CB. Data Analysis: LS, CB, AG and MVR. Original Draft Writing: LS, CB, MVR and AG. Review and Editing: All authors. LS had full access to all of the data in the study and takes responsibility for the integrity of the data and the accuracy of the data analysis.

\section{Acknowledgements}

Not applicable.

\section{References}

1. UNHCR Global Data Service. UNHCR - Global Trends 2019: Forced Displacement in 2019 [Internet]. Copenhagen, Denmark: UNHCR; 2020 Jun [cited $2020 \mathrm{Jul}$ 7]. Available from: https://www.unhcr.org/globaltrends2019/

2. UNHCR. Resettlement Data Finder [Internet]. [cited 2020 May 11]. Available from: https://rsq.unhcr.org/en/\#iqH9

3. Sawyer SM, Afifi RA, Bearinger LH, Blakemore S-J, Dick B, Ezeh AC, et al. Adolescence: a foundation for future health. The Lancet. 2012 Apr;379(9826):1630-40.

4. Arain, Haque, Johal, Mathur, Nel, Rais, et al. Maturation of the adolescent brain. Neuropsychiatr Dis Treat. 2013 Apr;449.

5. Bennouna C, Stark L, Wessells MG. Children and Adolescents in Conflict and Displacement. In: Song SJ, Ventevogel P, editors. Child, Adolescent and Family Refugee Mental Health [Internet]. Cham: Springer International Publishing; 2020 [cited 2020 Nov 11]. p. $17-36$. 
Available from: http://link.springer.com/10.1007/978-3-030-45278-0_2

6. Viner RM, Ozer EM, Denny S, Marmot M, Resnick M, Fatusi A, et al. Adolescence and the social determinants of health. The Lancet. 2012 Apr;379(9826):1641-52.

7. McNeely C. The teen years explained: a guide to healthy adolescent development. U.S.: Johns Hopkins Bloomberg; 2011.

8. Committee on Applying Lessons of Optimal Adolescent Health to Improve Behavioral Outcomes for Youth, Board on Children, Youth, and Families, Division of Behavioral and Social Sciences and Education, Health and Medicine Division, National Academies of Sciences, Engineering, and Medicine. Promoting Positive Adolescent Health Behaviors and Outcomes: Thriving in the 21st Century [Internet]. Graham R, Kahn NF, editors. Washington, D.C.: National Academies Press; 2020 [cited 2020 May 11]. Available from: https://www.nap.edu/catalog/25552

9. Bennouna C, Khauli N, Basir M, Allaf C, Wessells M, Stark L. School-based programs for Supporting the mental health and psychosocial wellbeing of adolescent forced migrants in high-income countries: A scoping review. Soc Sci Med. 2019 Oct 1;239:112558.

10. Miller KE, Jordans MJD. Determinants of Children's Mental Health in War-Torn Settings: Translating Research Into Action. Curr Psychiatry Rep. 2016 Jun;18(6):58.

11. Gallagher E. Mental health and Psychosocial Support and Social and Emotional Learning support for learning outcomes in conflictaffected settings. 2018 Oct 23;11.

12. Nassar-McMillan SC, Ajrouch KJ, Hakim-Larson J. Biopsychosocial Perspectives on Arab Americans Culture, Development, and Health [Internet]. Boston, MA: Springer US: Imprint: Springer; 2014 [cited 2020 May 4]. Available from: http://0dx.doi.org.cataleg.uoc.edu/10.1007/978-1-4614-8238-3

13. Heidi B, Miller AB, Baldwin H, Abdi S. New Directions in Refugee Youth Mental Health Services: Overcoming Barriers to Engagement. J Child Adolesc Trauma. 2011 Mar;4(1):69-85.

14. Waid J, Kelly M. Supporting family engagement with child and adolescent mental health services: A scoping review. Health Soc Care Community. 2020 Jan 17;hsc.12947.

15. Posselt M, McDonald K, Procter N, de Crespigny C, Galletly C. Improving the provision of services to young people from refugee backgrounds with comorbid mental health and substance use problems: addressing the barriers. BMC Public Health. 2017 Dec;17(1):280.

16. Baker JR, Raman S, Kohlhoff J, George A, Kaplun C, Dadich A, et al. Optimising refugee children's health/wellbeing in preparation for primary and secondary school: a qualitative inquiry. BMC Public Health. 2019 Dec;19(1):812.

17. Jones S, Bailey R, Brush K, Nelson B, Barnes S. What is the Same and What is Different? [Internet]. Harvard University's Graduate School of Education; 2016 May p. 15. Available from: https://easel.gse.harvard.edu/files/gse-easel-lab/files/words_matter_paper.pdf

18. Collaborative for Academic, Social, and Emotional Learning (CASEL). Districts [Internet]. CASEL. [cited 2020 Aug 27]. Available from: https://casel.org/districts-2/

19. Collaborative for Academic, Social, and Emotional Learning (CASEL). 2015 CASEL Guide: Effective Social and Emotional Learning Programs-Middle and High School Edition [Internet]. CASEL; 2015 [cited 2020 May 11]. Available from: http://secondaryguide.casel.org/casel-secondary-guide.pdf

20. Collaborative for Academic, Social, and Emotional Learning (CASEL). The CASEL Guide to Schoolwide SEL Essentials [Internet]. 2020 Mar [cited $2020 \mathrm{Jul}$ 1]. Available from: https://schoolguide.casel.org/resource/the-casel-guide-to-schoolwide-sel-essentials/

21. Greenberg MT, Domitrovich CE, Weissberg RP, Durlak JA. Social and Emotional Learning as a Public Health Approach to Education. Future Child. 2017;27(1):13-32.

22. Jones SM, Kahn J. The Evidence Base for How We Learn Supporting Students' Social, Emotional, and Academic Development [Internet]. National Commission on Social, Emotional, and Academic Development at The Aspen Institute; 2017 Sep [cited 2020 May 11]. Available from: https://assets.aspeninstitute.org/content/uploads/2017/09/SEAD-Research-Brief-11.1.17.pdf

23. Durlak JA, Weissberg RP, Dymnicki AB, Taylor RD, Schellinger KB. The Impact of Enhancing Students' Social and Emotional Learning: $A$ Meta-Analysis of School-Based Universal Interventions: Social and Emotional Learning. Child Dev. 2011 Jan;82(1):405-32.

24. Taylor RD, Oberle E, Durlak JA, Weissberg RP. Promoting Positive Youth Development Through School-Based Social and Emotional Learning Interventions: A Meta-Analysis of Follow-Up Effects. Child Dev. 2017 Jul;88(4):1156-71.

25. U.S. Department of Education. Newcomer Tool Kit [Internet]. U.S Department of Education; 2017 Sep [cited 2020 May 7]. Available from: https://www2.ed.gov/about/offices/list/oela/newcomers-toolkit/ncomertoolkit.pdf

26. Cho H, Wang XC, Christ T. Social-Emotional Learning of Refugee English Language Learners in Early Elementary Grades: Teachers' Perspectives. J Res Child Educ. 2019 Jan 2;33(1):40-55.

27. Beyer LN. Social and Emotional Learning and Traditionally Underserved Populations [Internet]. American Youth Policy Forum; 2017 p. 25. Available from: https://www.aypf.org/wp-content/uploads/2017/10/SEL-Special-Populations_Final.pdf

Page $12 / 15$ 
28. Sciuchetti MB. Addressing inequity in special education: An integrated framework for culturally responsive social emotional practice. Psychol Sch. 2017 Dec;54(10):1245-51.

29. Jagers RJ, Rivas-Drake D, Borowski T. Equity \& Social and Emotional Learning: A Cultural Analysis [Internet]. 2018 Nov [cited 2020 Jul 11]. Available from: https://measuringsel.casel.org/wp-content/uploads/2018/11/Frameworks-Equity.pdf

30. Kaler-Jones C. When SEL is Used as Another Form of Policing [Internet]. Medium. 2020 [cited 2020 Jul 19]. Available from: https://medium.com/@justschools/when-sel-is-used-as-another-form-of-policing-fa53cf85dce4

31. Madda MJ. Dena Simmons: Without context, social-emotional learning can backfire. [Internet]. 2019. Available from: https://www.edsurge.com/news/2019-05-15-dena-simmons-without-context-social-emotional-learning-can-backfire

32. Starr JP. On Leadership: Can we keep SEL on course? Phi Delta Kappan. 2019 May;100(8):70-1.

33. Ross R. School climate and equity [Internet]. New York, NY: National School Climate Center (NSCC); 2013 Feb [cited 2020 Jul 21]. (School Climate Practice Briefs). Available from: https://www.schoolclimate.org/themes/schoolclimate/assets/pdf/practice/sc-brief-equity.pdf

34. Coulston C, Smith K. School climate and inclusion [Internet]. New York, NY: National School Climate Center (NSCC); 2013 Feb [cited 2020 Jul 21]. (School Climate Practice Briefs). Available from: https://www.schoolclimate.org/themes/schoolclimate/assets/pdf/practice/scbrief-inclusion.pdf

35. Jagers R, Rivas-Drake D, Borowski T. Toward Transformative Social and Emotional Learning: Using an Equity Lens. $2018 ; 7$.

36. Jagers RJ, Rivas-Drake D, Williams B. Transformative Social and Emotional Learning (SEL): Toward SEL in Service of Educational Equity and Excellence. Educ Psychol. 2019 Jul 3;54(3):162-84.

37. Williams BV, Jagers RJ. Transformative Social and Emotional Learning: Work Notes on an Action Research Agenda. Urban Educ. 2020 Jul 25;004208592093334.

38. Simmons DN, Brackett MA, Adler N. Applying an Equity Lens to Social, Emotional, and Academic Development [Internet]. Edna Bennett Pierce Prevention Research Center, Pennsylvania State University; 2018 [cited 2020 Aug 27] p. 13. Available from: https://www.rwjf.org/en/library/research/2018/06/applying-an-equity-lens-to-social-emotional-and-academic-development.html

39. Panter-Brick C, Goodman A, Tol W, Eggerman M. Mental Health and Childhood Adversities: A Longitudinal Study in Kabul, Afghanistan. J Am Acad Child Adolesc Psychiatry. 2011 Apr;50(4):349-63.

40. IASC. IASC Guidelines on Mental Health and Psychosocial Support in Emergency Settings [Internet]. American Psychological Association; 2008 [cited 2020 Jul 11]. Available from: http://doi.apa.org/get-pe-doi.cfm?doi=10.1037/e518422011-002

41. Stark L, Robinson MV, Seff I, Hassan W, Allaf C. SALaMA study protocol: a mixed methods study to explore mental health and psychosocial support for conflict-affected youth in Detroit, Michigan. BMC Public Health. 2020 Jan 10;20(1):38.

42. Bennouna C, Ocampo MG, Cohen F, Basir M, Allaf C, Wessells M, et al. Ecologies of care: mental health and psychosocial support for waraffected youth in the U.S. Confl Health. 2019 Dec;13(1):47.

43. Seff I, Gillespie A, Bennouna C, Hassan W, Robinson MV, Wessells M, et al. Psychosocial well-being, mental health, and available supports in an Arab enclave: Exploring outcomes for foreign-born and U.S.-born adolescents. Rev.

44. Refugee Processing Center (RPC). Interactive reporting: Admissions and arrivals [Internet]. 2020 [cited 2020 Apr 30 ]. Available from: https://ireports.wrapsnet.org/Interactive-Reporting/EnumType/Report?ltemPath=/rpt_WebArrivalsReports/Map\%20-

\%20Arrivals\%20by\%20State\%20and\%20Nationality

45. Office of Refugee Resettlement. FY 2015 Served Populations by State and Country of Origin (all served populations) [Internet]. Office of Refugee Resettlement. 2016 [cited 2020 Apr 30]. Available from: https://www.acf.hhs.gov/orr/resource/fy-2015-served-populations-bystate-and-country-of-origin-refugees-only

46. Harrisonburg City Public Schools (HCPS). Enrollment of English learners [Internet]. 2017 [cited 2020 May 5]. Available from: https://harrisonburg.k12.va.us/files/user/1/file/9-29-17-EL-Birth-Countries-and-Languages.pdf

47. Austin Independent School District (aISD). Bilingual and English as a Second Language Program and Demographic Summary, 20182019 [Internet]. 2019 [cited 2020 May 5]. Available from: https://www.austinisd.org/sites/default/files/dre-

surveys/18.22_Bilingual_and\%20English_as_a_Second_Language_Program_and_Demographic_Summary_2018_2019.pdf

48. Arab American Institute Foundation. Demographics [Internet]. Arab American Institute Foundation. [cited 2019 Oct 10]. Available from: https://assets.nationbuilder.com/aai/pages/9843/attachments/original/1551198642/National_Demographics_SubAncestries_2018.pdf? 1551198642

49. Global Educational Excellence (GEE). Who We Are [Internet]. [cited 2020 May 5]. Available from: https://gee-edu.com/about/

50. Michigan's Center for Educational Performance and Information. Student Count Snapshot - English Learners [Internet]. 2019 [cited 2020 Aug 8]. Available from: https://www.mischooldata.org/DistrictSchoolProfiles2/StudentInformation/StudentCounts/StudentCount2.aspx

51. Ager A, Stark L, Potts A. Participative Ranking Methodology: A Brief Guide: Version 1.1. 2010.

Page 13/15 
52. Stark L, Ager A, Wessells M, Boothby N. Developing culturally relevant indicators of reintegration for girls, formerly associated with armed groups in Sierra Leone using a participative ranking methodology. Interv Int J Ment Health Psychosoc Work Couns Areas Armed Confl. 2009;7(1):4-16.

53. Ager A, Bancroft C, Berger E, Stark L. Local constructions of gender-based violence amongst IDPs in northern Uganda: analysis of archival data collected using a gender- and age-segmented participatory ranking methodology. Confl Health. 2018 Dec;12(1):10.

54. Horn R. Inter-Agency First Phase Child Welfare Assessment: Gambella Region, Ethiopia. 2009 Nov 18;89.

55. Boyatzis RE. Transforming qualitative information: Thematic analysis and code development. Thousand Oaks, CA, US: Sage Publications, Inc; 1998. xvi, 184 p. (Transforming qualitative information: Thematic analysis and code development.).

56. Braun V, Clarke V, Hayfield N, Terry G. Thematic Analysis. In: Liamputtong P, editor. Handbook of Research Methods in Health Social Sciences [Internet]. Singapore: Springer Singapore; 2019 [cited 2019 Oct 10]. p. 843-60. Available from: https://doi.org/10.1007/978-98110-5251-4_103

57. Bennouna C, Stark L. Ethical and Methodological Considerations for Researching Children Exposed to Political Violence. In: Handbook of Political Violence and Children [Internet]. Oxford University Press; 2020 [cited 2020 Oct 31]. p. 125-58. Available from: https://oxford.universitypressscholarship.com/view/10.1093/oso/9780190874551.001.0001/oso-9780190874551-chapter-5

58. Birman BD, Tran N. When worlds collide: Academic adjustment of Somali Bantu students with limited formal education in a U.S. elementary school. Int J Intercult Relat. 2017 Sep;60:132-44.

59. Rogoff B, Moore L, Najafi B, Dexter A, Correa-Chávez M, Solís J. Children's Development of Cultural Repertoires through Participation in Everyday Routines and Practices. In: Handbook of socialization: Theory and research. New York, NY, US: The Guilford Press; 2007. p. 490-515.

60. Lamont M, Welburn JS, Fleming CM. Responses to Discrimination and Social Resilience Under Neoliberalism. In: Maurer A, editor. New Perspectives on Resilience in Socio-Economic Spheres [Internet]. Wiesbaden: Springer Fachmedien Wiesbaden; 2016 [cited 2020 Aug 9]. p. 143-76. Available from: http://link.springer.com/10.1007/978-3-658-13328-3_7

61. Garner PW, Mahatmya D, Brown EL, Vesely CK. Promoting Desirable Outcomes Among Culturally and Ethnically Diverse Children in Social Emotional Learning Programs: a Multilevel Heuristic Model. Educ Psychol Rev. 2014 Mar;26(1):165-89.

62. Rivas-Drake D, Lozada FT, Pinetta BJ, Jagers RJ. School-Based Social-Emotional Learning and Ethnic-Racial Identity Among African American and Latino Adolescents. Youth Soc. 2020 Oct;52(7):1331-54.

63. Schlund J, Jagers RJ, Schlinger M. Emerging Insights on Advancing Social and Emotional Learning (SEL) as a Lever for Equity and Excellence [Internet]. Chicago, IL: CASEL; 2020 Aug [cited 2020 Aug 31]. Available from: https://casel.org/wp-

content/uploads/2020/08/CASEL-Equity-Insights-Report.pdf

\section{Figures}




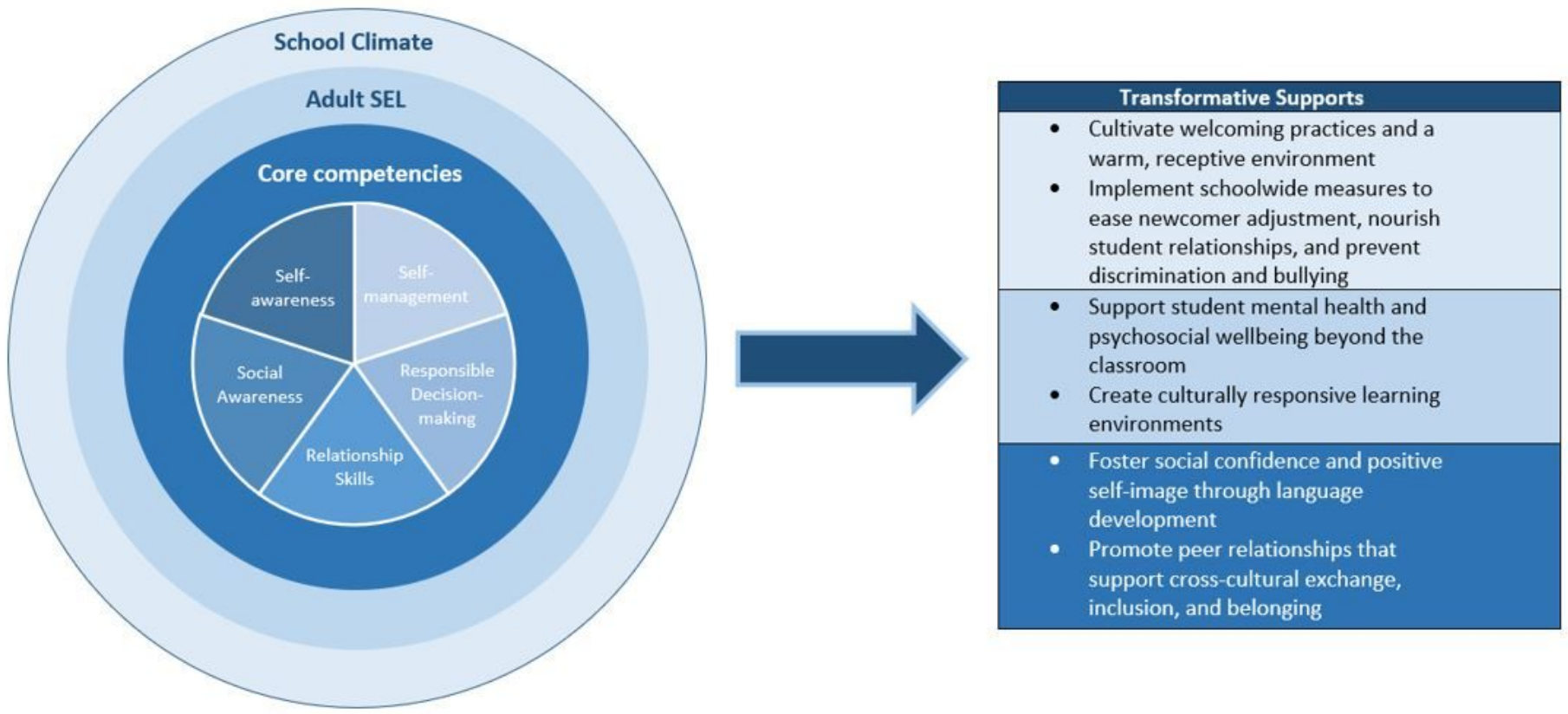

\section{Figure 1}

Evidence shows that educators who exhibit an 'assimilationist' stance in regard to newcomer students' acculturation process, with the belief that they should strictly abide by the norms of their new school and the dominant culture of their new country, can have negative effects on sense of belonging and academic success $(26,58)$. Thus, our findings illuminate the need to expand the transformative SEL framework to pay more attention to questions of acculturation and cultural responsiveness (see Figure 1). 